\title{
Inhibitory Effects of Epipolythiodioxopiperazine Fungal Metabolites on Isocitrate Lyase in the Glyoxylate Cycle of Candida albicans
}

\author{
Ji-Yeon Hwang ${ }^{1}$, Beomkoo Chung ${ }^{2}$, Oh-Seok Kwon ${ }^{1}$, Sung Chul Park ${ }^{1}$, Eunji Cho ${ }^{2}$, Dong-Chan Oh ${ }^{1}$, \\ Jongheon Shin $1, *$ (i) and Ki-Bong $\mathrm{Oh}^{2, *}$ \\ 1 Natural Products Research Institute, College of Pharmacy, Seoul National University, Seoul 08826, Korea; \\ yahyah7@snu.ac.kr (J.-Y.H.); ideally225@snu.ac.kr (O.-S.K.); sungchulpark@snu.ac.kr (S.C.P.); \\ dongchanoh@snu.ac.kr (D.-C.O.) \\ 2 Department of Agricultural Biotechnology, College of Agriculture and Life Sciences, \\ Seoul National University, Seoul 08826, Korea; beomkoo01@snu.ac.kr (B.C.); eunji525@snu.ac.kr (E.C.) \\ * Correspondence: shinj@snu.ac.kr (J.S.); ohkibong@snu.ac.kr (K.-B.O.); \\ Tel.: +82-2-880-2484 (J.S.); +82-2-880-4646 (K.-B.O.)
}

check for updates

Citation: Hwang, J.-Y.; Chung, B.; Kwon, O.-S.; Park, S.C.; Cho, E.; Oh, D.-C.; Shin, J.; Oh, K.-B.

Inhibitory Effects of

Epipolythiodioxopiperazine Fungal Metabolites on Isocitrate Lyase in the Glyoxylate Cycle of Candida albicans. Mar. Drugs 2021, 19, 295. https:// doi.org/10.3390/md19060295

Academic Editor: Bill J. Baker

Received: 30 April 2021

Accepted: 20 May 2021

Published: 22 May 2021

Publisher's Note: MDPI stays neutral with regard to jurisdictional claims in published maps and institutional affiliations.

Copyright: (c) 2021 by the authors. Licensee MDPI, Basel, Switzerland. This article is an open access article distributed under the terms and conditions of the Creative Commons Attribution (CC BY) license (https:/ / creativecommons.org/licenses/by/ $4.0 /)$.

\begin{abstract}
Four epipolythiodioxopiperazine fungal metabolites (1-4) isolated from the sponge-derived Aspergillus quadrilineatus FJJ093 were evaluated for their capacity to inhibit isocitrate lyase (ICL) in the glyoxylate cycle of Candida albicans. The structures of these compounds were elucidated using spectroscopic techniques and comparisons with previously reported data. We found secoemestrin C (1) (an epitetrathiodioxopiperazine derivative) to be a potent ICL inhibitor, with an inhibitory concentration of $4.77 \pm 0.08 \mu \mathrm{M}$. Phenotypic analyses of $I C L$-deletion mutants via growth assays with acetate as the sole carbon source demonstrated that secoemestrin C (1) inhibited C. albicans ICL. Semiquantitative reverse-transcription polymerase chain reaction analyses indicated that secoemestrin $\mathrm{C}$ (1) inhibits ICL mRNA expression in C. albicans under $\mathrm{C}_{2}$-assimilating conditions.
\end{abstract}

Keywords: epipolythiodioxopiperazines; sponge-derived fungus; Aspergillus quadrilineatus; Candida albicans; isocitrate lyase

\section{Introduction}

The glyoxylate cycle, which provides an efficient strategy for converting acetyl-CoA into anaplerotic compounds, is a modified form of the tricarboxylic acid cycle. This ability is a feature shared by microorganisms, plants, and certain invertebrates $[1,2]$. The function of the glyoxylate cycle has been confirmed by analyzing mutants of pathogenic microorganisms that lack isocitrate lyase (ICL), a key enzyme in the glyoxylate cycle [3,4]. Investigations into glyoxylate cycle regulation during microbial growth on acetate have revealed the importance of this pathway in bacterial and fungal pathogenesis. The ICL expression is upregulated in the pulmonary bacterium Mycobacterium tuberculosis during macrophage infection [5], in the plant pathogen Magnaporthe grisea during rice infection [6], and in Candida albicans, a pathogenic fungus that can cause serious illness in humans [7], during macrophage infection. A C. albicans mutant strain lacking ICL was found to be markedly less virulent than the wild-type strain in a mouse model of systemic candidiasis [8]. As the glyoxylate cycle is absent in mammalian cells, ICL has become an attractive target for antifungal drug discovery [9-11].

Epidithiodioxopiperazines are toxic secondary alkaloid metabolites synthesized only by fungi; however, their biological function is unknown. Thus, extensive research has been conducted to determine their structures, biosynthetic pathways, functions, and bioactivity [12]. Almost 20 distinct epidithiodioxopiperazine families have been identified and characterized since the discovery of gliotoxin produced by the wood fungus Gliocladium fimbriatum [13]. This unique class of natural compounds is characterized by an 
internal dioxopiperazine group attached via a disulfide bridge, which is responsible for the potent biological activity exhibited by epidithiodioxopiperazines [14-16]. Epidithiodioxopiperazines contain at least one aromatic amino acid and can be categorized as tyrosine- or phenylalanine-derived, or tryptophan-derived compounds [12]. For example, the dioxopiperazine ring of secoemestrin $C(\mathbf{1})$ is derived biosynthetically from tyrosine or phenylalanine. Diverse bioactivities of epidithiodioxopiperazines have been reported, including antifungal, antibacterial, antiviral, and anticancer activities. The potent effects of epidithiodioxopiperazines are due to the presence of the disulfide bridge, which can inactivate proteins by reacting with thiol groups and generate reactive oxygen species by redox cycling [12,17-21].

While searching for secondary metabolites of biological significance from marine organisms, we encountered Aspergillus quadrilineatus strain FJJ093, which we isolated from an unidentified sponge collected off the shore of Jeju Island, Republic of Korea. In this study, we cultured A. quadrilineatus strain FJJ093 on a semi-solid rice medium, and an organic compound extracted from this culture exhibited inhibitory activity toward C. albicans ICL. We employed diverse chromatographic methods to achieve activity-guided separation of the organic extract, leading to the isolation of four epipolythiodioxopiperazine alkaloids (1-4). Although the diverse biological properties of the isolated compounds, such as antibacterial, antifungal, immunosuppressive, and anti-inflammatory activities, are well established $[12,22]$, the ICL inhibitory activity of these compounds has not been investigated.

\section{Results}

\subsection{Isolation and Structural Elucidation}

Aspergillus quadrilineatus strain FJJ093 was cultured in semi-solid rice medium, and epipolythiodioxopiperazine alkaloid compounds were extracted from the culture using ethyl acetate. After evaporation of the solvent, the remaining extract was separated by reverse-phase $C_{18}$ vacuum flash chromatography using sequential mixtures of water and methanol, acetone, and ethyl acetate. Based on our ${ }^{1} \mathrm{H}$ nuclear magnetic resonance (NMR) results, the fractions eluted with 40:60 and 20:80 water-methanol mixtures were selected for separation by semi-preparative high-performance liquid chromatography (HPLC) and purified by analytical HPLC to yield four compounds. Using combined spectroscopic analyses, including ${ }^{1} \mathrm{H}$ and ${ }^{13} \mathrm{C}$ NMR, two-dimensional (2D) NMR spectral analyses (correlated spectroscopy, heteronuclear single quantum coherence spectroscopy, and heteronuclear multiple bond correlation), and ultraviolet spectroscopy, we identified the isolated compounds $\mathbf{1 - 4}$ as the following epipolythiodioxopiperazine alkaloids: secoemestrin C (1) [23], dethiosecoemestrin (2) [24], emestrin (3) [25,26], and emestrin B (4) [27] (Figure 1). The obtained spectroscopic data were highly similar to those of previous reports (Supplementary Materials).

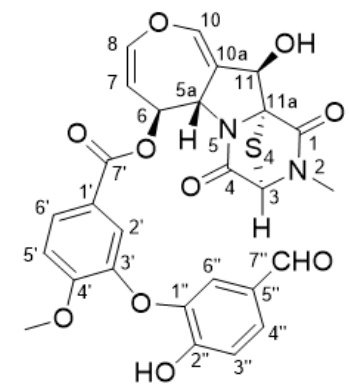

1

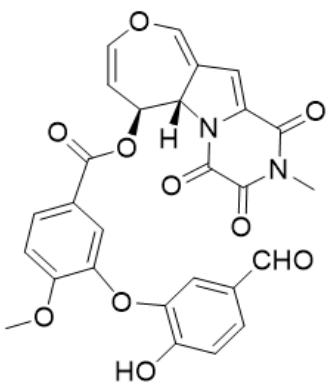

2

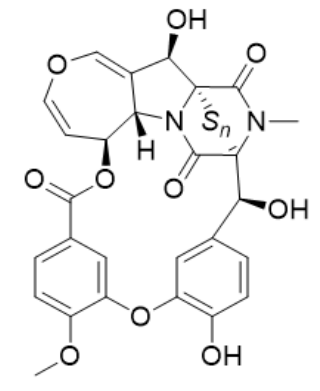

$3 n=2$

$4 n=3$

Figure 1. Chemical structures of compounds 1-4. Secoemestrin C (1), dethiosecoemestrin (2), emestrin (3), and emestrin B (4). 


\subsection{ICL Inhibitory Activity and Antifungal Activity}

The preparation of recombinant ICL cloned from C. albicans ATCC10231 was performed as described previously [28]. The inhibitory activities of secoemestrin C (1), dethiosecoemestrin (2), emestrin (3), and emestrin B (4) against purified recombinant ICL were evaluated according to a previously documented procedure [29]. The production of ICL-catalyzed glyoxylate phenylhydrazone from phenylhydrazine and isocitrate was measured using a spectrophotometer at an absorbance wavelength of $324 \mathrm{~nm}$. The half maximal inhibitory concentrations $\left(\mathrm{IC}_{50}\right)$ of compounds $\mathbf{1 - 4}$ are shown in Table 1 . Compounds $\mathbf{2 - 4}$ did not exhibit inhibitory activity toward ICL. By contrast, secoemestrin C (1) was a strong ICL inhibitor, with an $\mathrm{IC}_{50}$ of $4.77 \pm 0.08 \mu \mathrm{M}$ (Figure 2a). Notably, secoemestrin C (1) was a more effective ICL inhibitor compared with the reference ICL inhibitor, 3-nitropropionate $\left(\mathrm{IC}_{50}=21.83 \pm 1.38 \mu \mathrm{M}\right)$.

Table 1. Inhibitory activities of compounds 1-4 against the ICL enzyme and growth of C. albicans ATCC10231.

\begin{tabular}{ccc}
\hline Compound & ICL IC $_{\mathbf{5 0}}, \boldsymbol{\mu M}$ & MIC $(\boldsymbol{\mu g} / \mathrm{mL})$ \\
\hline Secoemestrin C (1) & $4.77 \pm 0.08$ & $>128$ \\
Dethiosecoemestrin (2) & $>240.55$ & $>128$ \\
Emestrin (3) & $>214.02$ & $>128$ \\
Emestrin B (4) & $>203.16$ & $>128$ \\
3-Nitropropionate & $21.83 \pm 1.38$ & $>128$ \\
Amphotericin B & $\mathrm{ND}$ & 0.5 \\
\hline
\end{tabular}

Positive controls included 3-nitropropionate, a reference ICL inhibitor, and amphotericin B, a standard antifungal drug. Dimethyl sulfoxide (DMSO, $0.5 \%$ ) was used as a negative control. ND = not determined.

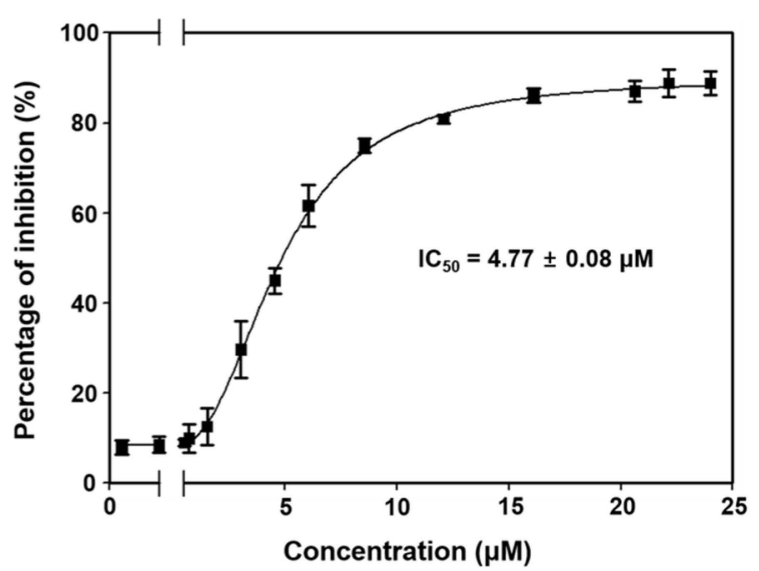

(a)

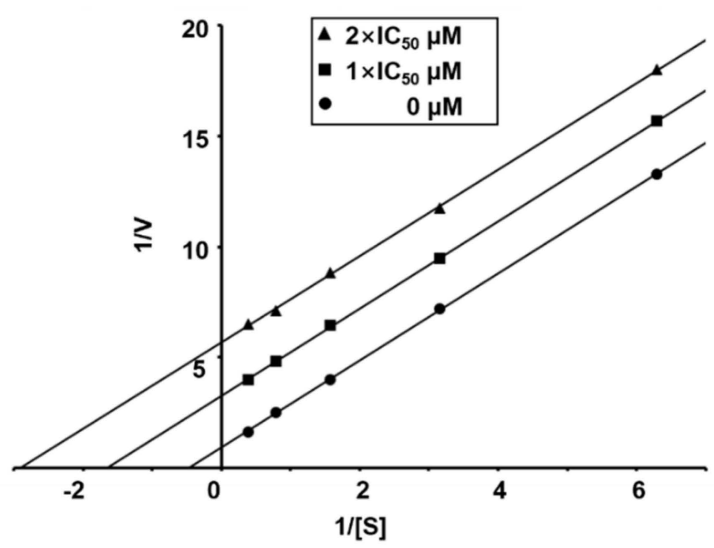

(b)

Figure 2. (a) Dose-dependent curve showing the inhibitory activity of secoemestrin C (1) against ICL cloned from C. albicans ATCC10231. Non-linear regression curve fitting was performed using GraphPad software ver. 8.0. The vertical bars indicate the standard errors $(n=3)$. (b) Lineweaver-Burk plot showing ICL inhibition by secoemestrin C (1). [S], substrate concentration in $\mathrm{mM} ; V$, reaction velocity $\left(\Delta \mathrm{A}_{324 \mathrm{~nm}} / \mathrm{min}\right)$.

To determine the ICL inhibition mechanism, kinetic analysis was performed using secoemestrin C (1). The inhibitor constant $(\mathrm{Ki})$ was calculated by generating a LineweaverBurk plot. These data suggest that secoemestrin $C(\mathbf{1})$ behaved as an uncompetitive inhibitor $(\mathrm{Ki}=263.8 \mu \mathrm{M})($ Figure $2 \mathrm{~b})$. Moreover, the binding of secoemestrin $\mathrm{C}(\mathbf{1})$ to the enzyme was irreversible because the enzyme activity was not recovered by dialysis within $1 \mathrm{~h}$, indicating the possible existence of thiol-reactive groups in ICL. In addition, compounds 14 did not inhibit C. albicans SC5314 cultured in glucose (minimum inhibitory concentration $(\mathrm{MIC})>128 \mu \mathrm{g} / \mathrm{mL}$ ) (Table 1). 


\subsection{Inhibition of $\mathrm{C}_{2}$ Substrate Utilization}

Following phagocytosis by macrophages, C. albicans undergoes a metabolic shift from glycolysis to the glyoxylate cycle, enabling cells to utilize $C_{2}$ carbon sources $[7,8]$. Therefore, we hypothesized that the ICL inhibitor reduces nutrient uptake capacity and impedes the survival of $C$. albicans within macrophages. To determine whether secoemestrin $C$ (1) affects $C_{2}$ substrate use, C. albicans strains (SC5314, ATCC10231, ATCC10259, ATCC11006, and ATCC18804) were grown in a yeast nitrogen base (YNB) broth containing either glucose or acetate. secoemestrin C (1) exhibited inhibitory effects on C. albicans growing on acetate (MIC $=32-64 \mu \mathrm{g} / \mathrm{mL}$ ), but not on C. albicans growing in the presence of glucose (Table 2). These results indicate that secoemestrin C (1) affects ICL-dependent growth of $C$. albicans under $\mathrm{C}_{2}$-assimilating conditions.

Table 2. Effect of secoemestrin C (1) on C. albicans strains grown in glucose or acetate as their sole carbon source.

\begin{tabular}{|c|c|c|c|c|}
\hline \multirow{3}{*}{ Strain } & \multicolumn{4}{|c|}{ MIC ( $\mu \mathrm{g} / \mathrm{mL})$} \\
\hline & \multicolumn{2}{|c|}{ Glucose } & \multicolumn{2}{|c|}{ Acetate } \\
\hline & Secoemestrin C (1) & Amph B & Secoemestrin C (1) & Amph B \\
\hline SC5314 & $>128$ & 0.5 & 64 & 0.5 \\
\hline ATCC10231 & $>128$ & 0.5 & 64 & 0.5 \\
\hline ATCC10259 & $>128$ & 1 & 32 & 0.5 \\
\hline ATCC11006 & $>128$ & 0.5 & 64 & 0.5 \\
\hline ATCC18804 & $>128$ & 1 & 64 & 1 \\
\hline
\end{tabular}

C. albicans cells $\left(1 \times 10^{4} / \mathrm{mL}\right)$ were incubated with varying concentrations of secoemestrin $\mathrm{C}(\mathbf{1})$ for $72 \mathrm{~h}$ at $28{ }^{\circ} \mathrm{C}$ in YNB medium containing $2 \%$ glucose or $2 \%$ potassium acetate. Amph B (amphotericin B) was used as a positive control.

\subsection{Effects of Secoemestrin C (1) on Growth Phenotype and ICL mRNA Expression}

To determine the effects of secoemestrin $C(\mathbf{1})$ on $C$. albicans growth under $\mathrm{C}_{2}$-assimilating conditions, phenotypic analyses of ICL-deletion mutants were also performed using C. albicans strains SC5314 (wild type), MRC10 ( $\Delta i c l)$, and MRC11 $(\triangle i c l+I C L)$. After preculture, each strain was streaked onto YNB agar plates supplemented with glucose or potassium acetate with or without $64 \mu \mathrm{g} / \mathrm{mL}$ secoemestrin C (1). All strains exhibited normal phenotypes on glucose and on glucose plus secoemestrin C (1). However, MRC10 failed to grow on acetate. Furthermore, all tested $C$. albicans strains failed to grow on YNB agar supplemented with acetate and secoemestrin C (1) (Figure 3a). These results indicate that $C$. albicans ICL is involved in the growth of the fungus on $C_{2}$ substrates.

We further investigated the effects of secoemestrin C (1) on ICL mRNA expression in C. albicans using a semi-quantitative reverse-transcription polymerase chain reaction (RTPCR). As shown in Figure 3b, the ICL mRNA levels in the wild-type (SC5314) and the ICLcomplemented mutant (MRC11) were undetectable in the YNB broth medium containing glucose but were strongly induced in the acetate-containing medium. The intensity of the PCR band corresponding to the ICL product decreased with increasing secoemestrin $\mathrm{C}$ (1) concentrations in the cells grown in acetate. GPDH expression was detected in all treatment conditions. These results indicate that secoemestrin $C(\mathbf{1})$ inhibits ICL mRNA expression in C. albicans under $\mathrm{C}_{2}$-assimilating conditions. 


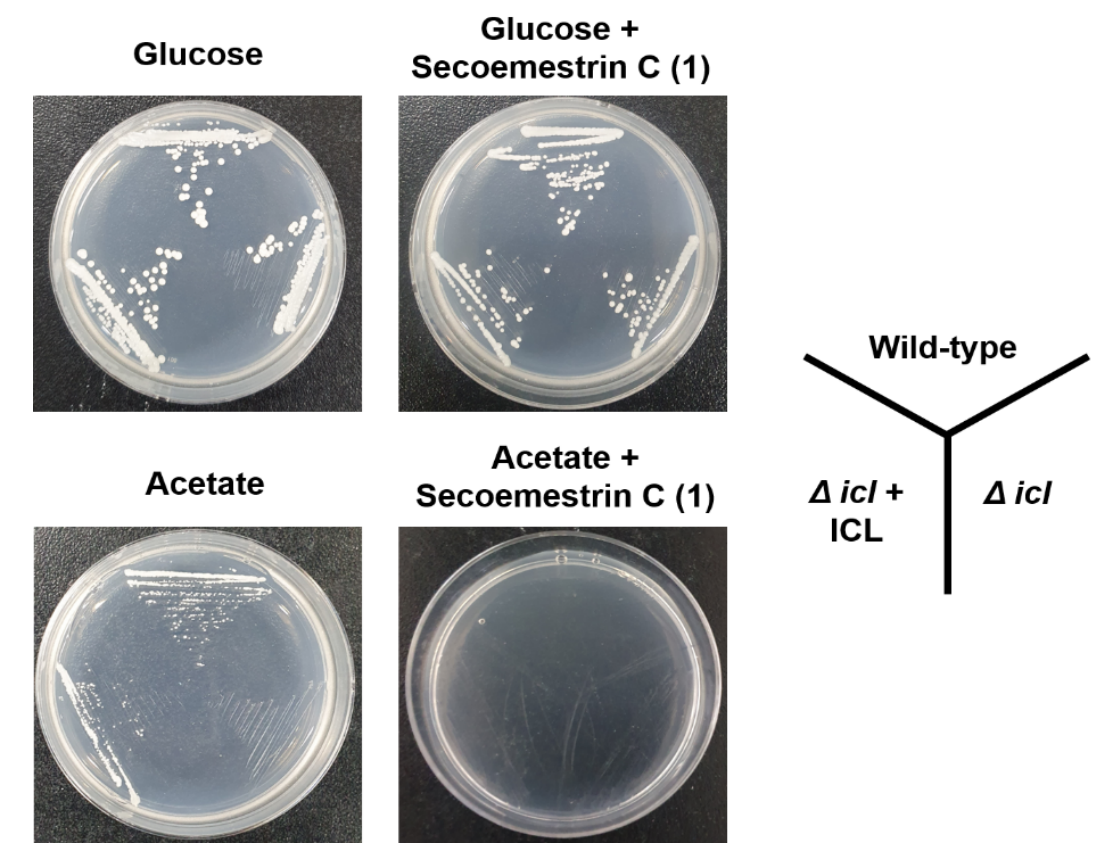

(a)

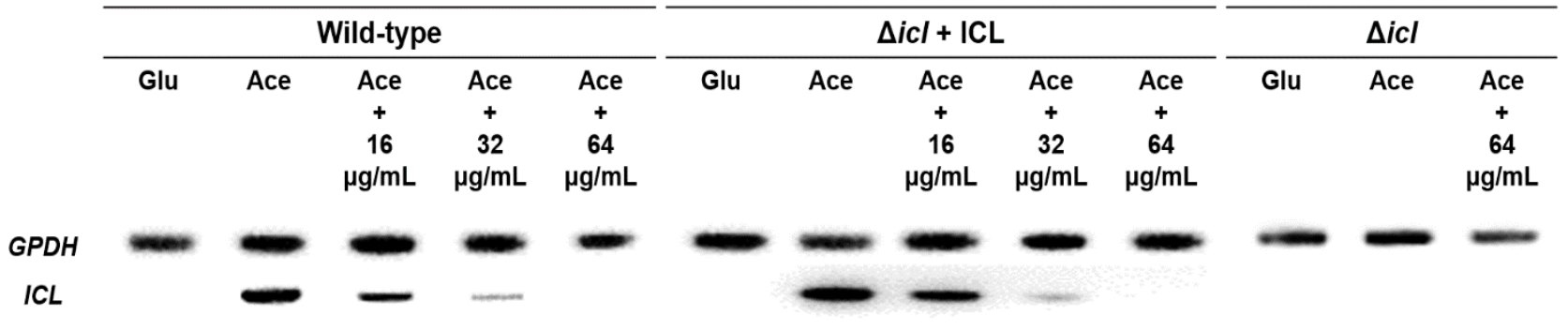

(b)

Figure 3. Inhibitory activity of secoemestrin C (1) toward the growth and ICL mRNA expression of C. albicans. (a) C. albicans strains SC5314 (wild-type), MRC10 $(\Delta i c l)$, and MRC11 $(\Delta i c l+I C L)$ were cultured on YNB agar plates containing $2 \%$ glucose or $2 \%$ potassium acetate as a carbon source with or without $64 \mu \mathrm{g} / \mathrm{mL}$ secoemestrin $\mathrm{C}$ (1) for 2 days at $28^{\circ} \mathrm{C}$. (b) Strains were grown in YNB broth containing $2 \%$ glucose, collected by centrifugation, and transferred to YNB containing $2 \%$ glucose (Glu), $2 \%$ potassium acetate (Ace), or $2 \%$ Ace + secoemestrin C (1) $\left(16,32\right.$, or $64 \mu \mathrm{g} / \mathrm{mL}$ ) and cultured for $4 \mathrm{~h}$ at $28{ }^{\circ} \mathrm{C}$. ICL mRNA expression was analyzed by RT-PCR. Glyceraldehyde-3-phosphate dehydrogenase (GPDH), a housekeeping gene, was measured as a loading control.

\section{Discussion}

Recent studies have shown that the glyoxylate cycle plays an important role in the pathogenicity of microorganisms. For example, ICL-deletion mutants of M. tuberculosis show impaired survival in vivo [5]. Similarly, Lorenz and Fink [6] reported that the glyoxylate cycle is essential for the survival of C. albicans in mammalian systems and ICL is required to be fully virulent. The interior environment of macrophage phagolysosomes is abundant in fatty acids or their breakdown products, which can be utilized by $C$. albicans as $C_{2}$ carbon sources via the glyoxylate pathway. C. albicans mutant strains lacking ICL were found to be markedly less virulent than the wild-type in a mouse model of systemic candidiasis [8]. Therefore, ICL has become an attractive target for antifungal drug development. In this study, four epipolythiodioxopiperazine metabolites were isolated from the sponge-derived fungus A. quadrilineatus strain FJJ093, and their structures and inhibitory activities toward ICL derived from $C$. albicans were evaluated. We found that compound $\mathbf{1}$, an epitetrathiodioxopiperazine derivative, possesses potent ICL inhibitory activity. Phenotypic analyses of ICL-deletion mutants via growth assays and semi-quantitative RT-PCR 
demonstrated that secoemestrin C (1) inhibited ICL expression in C. albicans under $\mathrm{C}_{2}-$ assimilating conditions.

Emestrin (3), a representative tyrosine and/or phenylalanine-derived epidithiodioxopiperazine, was first isolated in 1985 from the fungus Emericella striata and later from E. quadrilineata, E. foveolata, E. acristata, and E. parvathecia [12,23-27]. This compound displays potent antifungal and antibacterial activities but is also highly toxic to mammals [12]. Secoemestrin C (1), isolated from E. foveolata [23] and Aspergillus nidulans [22], is the first example of an epitetrathiodioxopiperazine derivative with potential immunosuppressive and anti-inflammatory activities. Trisulfide emestrin B (4) and trioxopiperazine dethiosecoemestrin (2) were later isolated from E. striata [24,27]. In this study, among the epipolythiodioxopiperazine fungal metabolites, secoemestrin $C(\mathbf{1}$, tetrathio) exhibited potent ICL inhibitory activity, with an $\mathrm{IC}_{50}$ of $4.77 \pm 0.08 \mu \mathrm{M}$. However, emestrin (3) and emestrin B (4) (dithio and trithio, respectively) showed no inhibitory activity against ICL. Interestingly, dethiosecoemestrin (2) (dethio form of secoemestrin C (1)) also exhibited no inhibitory activity against ICL, which suggests that the tetrathio moiety plays a role in ICL inhibition.

The genes encoding proteins of the glyoxylate cycle are required for virulence in $M$. tuberculosis and C. albicans, both of which can survive inside macrophages [5,7]. Based on these findings, we hypothesized that inhibitors of glyoxylate cycle enzymes block nutrient uptake and reduce the survival capacity of these pathogens following engulfment by macrophages. To investigate this, we examined the effects of secoemestrin $C(\mathbf{1})$ on the growth phenotype and ICL mRNA expression of $C$. albicans wild-type and ICL-deletion mutant strains (Figure 3). The growth assay revealed that secoemestrin C (1) specifically inhibited the ICL enzyme because no growth of strains SC5314 (wild-type) and MRC11 (ICL-complemented mutant) was observed on the YNB agar plates containing acetate and $64 \mu \mathrm{g} / \mathrm{mL}$ secoemestrin C (1). Moreover, ICL transcript levels were reduced as a result of treatment with secoemestrin $C(\mathbf{1})$.

By comparison, it seems that a tetrathio bridge between the C11a and 3 in the piperazine ring of secoemestrin C (1) is needed for ICL inhibition. Emestrin (3) and emestrin B (4), containing dithio or trithio bridges, are not inhibitors of ICL. Moreover, secoemestrin C (1) inhibits ICL mRNA expression rather than having a direct effect on the enzyme active site. Further studies are required to clarify the relationship between ICL activity inhibition and the reduction of ICL expression and to identify the main cellular target of secoemestrin C (1).

\section{Materials and Methods}

\subsection{General Experimental Procedures}

${ }^{1} \mathrm{H},{ }^{13} \mathrm{C}$, and $2 \mathrm{D}$ (correlated spectroscopy, heteronuclear single quantum coherence spectroscopy, heteronuclear multiple bond correlation) NMR measurements were performed using deuterated dimethyl sulfoxide (DMSO) and deuterated chloroform solutions using Bruker Avance-400, -600 and -800 instruments (Bruker, Billerica, MA, USA). Solvent peaks at $\delta_{\mathrm{H}} 2.50 / \delta_{\mathrm{C}} 39.50$ and $\delta_{\mathrm{H}} 7.26 / \delta_{\mathrm{C}} 77.16$ were applied as internal standards for deuterated DMSO and chloroform, respectively. Low-resolution electrospray ionization mass spectrometry was performed using the Agilent Technologies 6130 quadrupole mass spectrometer connected to the Agilent Technologies 1200 series HPLC system (Agilent Technologies, Santa Clara, CA, USA). High-resolution ESI mass spectrometric data were obtained at the National Instrumentation Center for Environmental Management (Seoul, Korea) on a Q-TOF 5600 instrument equipped with a Dionex U-3000 HPLC system. Optical rotations were measured on a JASCO P2000 polarimeter (Jasco, Tokyo, Japan) using a $1 \mathrm{~cm}$ cell. Semi-preparative HPLC separations were performed using the Spectrasystem p2000 pump equipped with the Spectrasystem RI-150 refractive index detector (Thermo Scientific, Waltham, MA, USA). All solvents used were spectroscopy grade or distilled in glass prior to use. 


\subsection{Marine Fungal Strain Isolation and Identification}

The fungal strain FJJ093 was isolated from an unidentified sponge collected during a diving expedition at a depth of $30 \mathrm{~m}$ off the coast of Jeju Island, Republic of Korea, on 29 September 2014. The sponge specimen was macerated and diluted using sterile seawater. The diluted sponge sample $(1 \mathrm{~mL})$ was inoculated on yeast extract peptone glucose (YPG) agar plates ( $5 \mathrm{~g}$ yeast extract, $5 \mathrm{~g}$ peptone, $10 \mathrm{~g}$ glucose, $0.15 \mathrm{~g}$ penicillin $\mathrm{G}, 0.15 \mathrm{~g}$ streptomycin sulfate, $24.8 \mathrm{~g}$ Instant Ocean (Instant Ocean Spectrum Brands, Blacksburg, VA, USA), and $16 \mathrm{~g}$ agar in $1 \mathrm{~L}$ distilled water). The inoculated plates were incubated at $28{ }^{\circ} \mathrm{C}$ for 5 days. The fungal strain was identified via DNA amplification and sequencing of the genomic internal transcribed spacer region [30] and $\beta$-tubulin [31]. To achieve this, genomic DNA was extracted from FJJ093 mycelia using the i-Genomic BYF DNA Extraction Mini Kit (Intron Biotechnology, Seoul, Korea) according to the manufacturer's protocol. The $18 \mathrm{~S}$ rDNA (527/527) and $\beta$-tubulin (425/425) sequences of strain FJJ093 exhibited a 100\% identity to the Aspergillus quadrilineatus strain NRRL201 (type strain, GenBank accession number EF652433.1; homotypic GenBank synonym: Emericella quadrilineata). Thus, our strain was designated as Aspergillus quadrilineatus strain FJJ093 (GenBank accession number MK424491).

\subsection{Fungal Isolate Cultivation}

FJJ093 was cultured on a solid YPG medium without antibiotics for 7 days. An agar plug $\left(1 \times 1 \mathrm{~cm}^{2}\right)$ was inoculated into a $250 \mathrm{~mL}$ flask containing $100 \mathrm{~mL}$ YPG liquid medium and cultured for 7 days. Then, $10 \mathrm{~mL}$ of each FJJ093 culture was transferred to a $2.8 \mathrm{~L}$ Fernbach flask containing a semi-solid rice medium ( $200 \mathrm{~g}$ rice, $0.5 \mathrm{~g}$ yeast extract, $0.5 \mathrm{~g}$ malt extract, and $12.4 \mathrm{~g}$ Instant Ocean in $500 \mathrm{~mL}$ distilled water). FJJ093 inoculated with $1 \mathrm{~kg}$ rice medium was cultivated for 28 days at $28^{\circ} \mathrm{C}$, agitating once per week.

\subsection{Extraction and Isolation of Alkaloid Compounds}

FJJ093 cultivated on rice medium $(1 \mathrm{~kg})$ was macerated and subjected to an organic compound extraction with ethyl acetate $(1 \mathrm{~L} \times 3)$. The ethyl acetate was evaporated in vacuo, leaving behind a brown organic deposit $(7.2 \mathrm{~g})$. The remaining extract was separated by $\mathrm{C}_{18}$ reverse-phase vacuum flash chromatography using sequential mixtures of water and methanol (five fractions of water-methanol, gradient from 80:20 to 0:100), acetone, and ethyl acetate as eluents. Based on our ${ }^{1} \mathrm{H}$ NMR analysis, the fractions eluted with 40:60 (850 mg) and 20:80 (1000 mg) water-methanol were selected for further separation. The fraction that eluted at 40:60 water-methanol was separated by semi-preparative reverse-phase HPLC (YMC ODS-A column, $250 \times 10 \mathrm{~mm}$, particle size $5 \mu \mathrm{m}$; mobile phase, 60:40 water-methanol; flow rate, $1.8 \mathrm{~mL} / \mathrm{min}$ ) to isolate emestrin B (4) (retention time $\left[t_{R}\right]=50.1 \mathrm{~min}$ ). The 20:80 water-methanol fraction was separated by HPLC (mobile phase, 50:50 water-acetonitrile; flow rate, $1.8 \mathrm{~mL} / \mathrm{min}$ ) to obtain pure isolates of dethiosecoemestrin $(2)\left(\left[t_{R}\right]=26.8 \mathrm{~min}\right)$ and emestrin $(3)\left(\left[t_{R}\right]=24.8 \mathrm{~min}\right)$. Isolation of an additional peak $\left(t_{\mathrm{R}}=30.2 \mathrm{~min}\right.$ ) by analytical HPLC (YMC-ODS-A column, $4.6 \times 250 \mathrm{~mm}$, particle size $5 \mu \mathrm{m}$; mobile phase, $45: 55$ water-methanol; flow rate, $0.7 \mathrm{~mL} / \mathrm{min}$ ) yielded secoemestrin $\mathrm{C}$ (1) $\left(\left[t_{R}\right]=18.3 \mathrm{~min}\right)$ as an amorphous solid. The overall quantities of purified 1-4 were 3.9, $5.7,3.6$, and $4.8 \mathrm{mg}$, respectively.

secoemestrin C (1): $[\alpha]_{\mathrm{D}}^{25}-115.2$ (c 0.2, MeOH); HRESIMS $m / z$ 685.0034 $[\mathrm{M}+\mathrm{Na}]^{+}($calcd for $\mathrm{C}_{27} \mathrm{H}_{22} \mathrm{~N}_{2} \mathrm{O}_{10} \mathrm{~S}_{4} \mathrm{Na}$, 685.0049).

dethiosecoemestrin (2): $[\alpha]_{\mathrm{D}}^{25}-108.7\left(c\right.$ 0.2, MeOH); HRESIMS $m / z 533.1189[\mathrm{M}+\mathrm{H}]^{+}$(calcd for $\mathrm{C}_{27} \mathrm{H}_{21} \mathrm{~N}_{2} \mathrm{O}_{10}, 533.1191$ ).

emestrin (3): $[\alpha]_{\mathrm{D}}^{25}+70.0$ (c 0.1, MeOH); HRESIMS $m / z$ 597.0641 $[\mathrm{M}-\mathrm{H}]^{-}$(calcd for $\mathrm{C}_{27} \mathrm{H}_{21} \mathrm{~N}_{2} \mathrm{O}_{10} \mathrm{~S}_{2}$, 597.0643).

emestrin B (4): $[\alpha]_{\mathrm{D}}^{25}+93.7$ ( $c$ 0.2, MeOH); HRESIMS $m / z$ 597.0646 [M - S - H $]^{-}$(calcd for $\mathrm{C}_{27} \mathrm{H}_{21} \mathrm{~N}_{2} \mathrm{O}_{10} \mathrm{~S}_{2}$, 597.0643). 


\subsection{C. albicans Strains and Growth Medium}

The ICL gene was cloned from C. albicans strain ATCC10231 genomic DNA. C. albicans SC5314 (ATCC MYA-2876) (wild type), MRC10 ( $\triangle i c l)$ (ICL-deletion mutant), MRC11 $(\Delta i c l+I C L)(I C L-c o m p l e m e n t e d$ mutant), ATCC10261, ATCC18804, and ATCC11006 were used for the growth assay. The ICL-deletion mutant strains MRC10 and MRC11 were kindly provided by Prof. Michael C. Lorenz (The University of Texas Health Science Center at Houston) [8]. Each strain was subcultured in YNB broth (Difco Laboratories, Detroit, MI, USA) supplemented with $2 \%$ glucose at $28{ }^{\circ} \mathrm{C}$. For the ICL inhibitor addition, isolated compounds dissolved in DMSO were added to a final solvent concentration of $0.5 \%$ in all growth assays.

\subsection{ICL Inhibition Assay}

The preparation of the recombinant ICL protein from C. albicans ATCC10231 was performed as described in a previous paper [28]. We used the two synthetic primers IC1 (5'-AGAATTCCTACCATGCCTTACACTCC-3') and IC-2 (5'-CTTCGTCGACTCAAAA TTAAGCCTTG-3') to perform a PCR amplification of ICL. The ICL inhibitory activity of the test compounds were evaluated according to a previously described method [29]. The ICLcatalyzed formation of glyoxylate phenylhydrazone from isocitrate and phenylhydrazine substrates was measured using a spectrophotometer at an absorbance wavelength of $324 \mathrm{~nm}$. The inhibitory activity of the test compound was calculated relative to that of the DMSO control $(n=3)$. We used 3-nitropropionate as a positive control [32].

\subsection{In Vitro Growth Assay}

The antifungal activity of secoemestrin C (1), dethiosecoemestrin (2), emestrin (3), and emestrin B (4) was evaluated against C. albicans strains (SC5314, ATCC10231, ATCC10259, ATCC11006, and ATCC18804) using a previously documented procedure [33]. The growth of $C$. albicans was monitored in YNB broth with glucose or potassium acetate as the carbon source. The plates were incubated at $28^{\circ} \mathrm{C}$ for 3 days. The MIC of each test compound was determined by identifying the lowest concentration at which the compound inhibited fungal growth. Amphotericin B, an antifungal agent, was applied as a positive control.

\subsection{Growth Phenotype and ICL Expression Analysis}

Growth phenotype and ICL expression analysis were performed using $C$. albicans strains SC5314 (wild type), MRC10 $(\Delta i c l)$, and MRC11 $(\Delta i c l+I C L)$ according to a previously described method [34]. For the ICL expression analysis, total RNA from each sample was isolated using the RNeasy Mini Kit (Qiagen) and reverse-transcribed into CDNA using the Superscript III First-Strand Synthesis System (Invitrogen) according to the manufacturer's instructions. Semi-quantitative RT-PCR was conducted using ICL-specific primers: $5^{\prime}$ ATGCCTTACACTCCTATTGACATTCAAAA-3' (forward) and 5'-TAGATTCAGCTTCA GCCATCAAAGC-3' (reverse). The expression of the housekeeping gene glyceraldehyde-3phosphate dehydrogenase (GPDH) was measured as a loading control.

Supplementary Materials: The following are available online at https://www.mdpi.com/article/ 10.3390/md19060295/s1, Figures S1-S8: ${ }^{1} \mathrm{H}$ and ${ }^{13} \mathrm{C}$ NMR spectra of secoemestrin C (1), dethiosecoemestrin (2), emestrin (3), and emestrin B (4)., Table S1: The deviations of ${ }^{13} \mathrm{C}$ NMR chemical shifts of 1-4 with literature.

Author Contributions: J.-Y.H., O.-S.K. and S.C.P. carried out the isolation and structural elucidation; B.C. and E.C. carried out the ICL inhibition assays and gene expression analysis; D.-C.O. evaluated all data; J.S. and K.-B.O. supervised the research work and prepared the paper. All authors have read and agreed to the published version of the manuscript.

Funding: This research was supported by the Basic Science Research Program through the National Research Foundation (NRF-2018R1D1A1B07043375) of Korea funded by the Ministry of Education, Science, and Technology and the National Research Foundation (NRF-2021R1A4A2001251) funded by the Ministry of Science, ICT and Future Planning, Korea. 
Acknowledgments: The authors wish to thank Michael C. Lorenz for providing us with C. albicans ICL mutant strains. The authors also thank the Basic Science Research Institute in Daegu, Korea, for providing the mass data and the National Center for Inter-University Research Facilities (NCIRF), Seoul National University, for providing the NMR data.

Conflicts of Interest: The authors declare no conflict of interest.

\section{References}

1. Vanni, P.; Giachetti, E.; Pinzauti, G.; McFadden, B.A. Comparative structure, function and regulation of isocitrate lyase, an important assimilatory enzyme. Comp. Biochem. Physiol. Part B Comp. Biochem. 1990, 95, 431-458. [CrossRef]

2. Dunn, M.F.; Ramirez-Trujillo, J.A.; Hernández-Lucas, I.; Dunn, M. Major roles of isocitrate lyase and malate synthase in bacterial and fungal pathogenesis. Microbiology 2009, 155, 3166-3175. [CrossRef] [PubMed]

3. Kunze, M.; Pracharoenwattana, I.; Smith, S.M.; Hartig, A. A central role for the peroxisomal membrane in glyoxylate cycle function. Biochim. Biophys. Acta 2006, 1763, 1441-1452. [CrossRef] [PubMed]

4. Strijbis, K.; Distel, B. Intracellular acetyl unit transport in fungal carbon metabolism. Eukaryot. Cell 2010, 9, 1809-1815. [CrossRef]

5. McKinney, J.D.; Bentrup, K.H.Z.; Munoz-Elias, E.J.; Miczak, A.; Chen, B.; Chan, W.T.; Swenson, D.; Sacchettini, J.C.; Jacobs, W.R., Jr.; Russell, D.G. Persistence of Mycobacterium tuberculosis in macrophages and mice requires the glyoxylate shunt enzyme isocitrate lyase. Nature 2000, 406, 735-738. [CrossRef] [PubMed]

6. Wang, Z.Y.; Thornton, C.R.; Kershaw, M.J.; Debao, L.; Talbot, N.J. The glyoxylate cycle is required for temporal regulation of virulence by the plant pathogenic fungus Magnaporthe grisea. Mol. Microbiol. 2003, 47, 1601-1612. [CrossRef] [PubMed]

7. Lorenz, M.C.; Fink, G.R. The glyoxylate cycle is required for fungal virulence. Nature 2001, 412, 83-86. [CrossRef]

8. Ramirez, M.A.; Lorenz, M.C. Mutations in alternative carbon utilization pathways in Candida albicans attenuate virulence and confer pleiotropic phenotypes. Eukaryot. Cell 2007, 6, 280-290. [CrossRef]

9. Kratky, M.; Vinsova, J. Advances in mycobacterial isocitrate lyase targeting and inhibitors. Curr. Med. Chem. 2012, 19, 6126-6137. [CrossRef]

10. Greene, J.; Sheu, S.-S.; Gross, R.; Greenamyre, J.T. 3-Nitropropionic acid exacerbates N-methyl-d-aspartate toxicity in striatal culture by multiple mechanisms. Neuroscience 1998, 84, 503-510. [CrossRef]

11. Ko, Y.H.; Smith, B.L.; Wang, Y.; Pomper, M.G.; Rini, D.A.; Torbenson, M.S.; Hullihen, J.; Pedersen, P.L. Advanced cancers: Eradication in all cases using 3-bromopyruvate therapy to deplete ATP. Biochem. Biophys. Res. Commun. 2004, 324, 269-275. [CrossRef]

12. Welch, T.R.; Williams, R.M. Epidithiodioxopiperazines occurrence, synthesis and biogenesis. Nat. Prod. Rep. 2014, 31, 1376-1404. [CrossRef]

13. Weindling, R.; Emerson, O.H. The isolation of a toxic substance from the culture filtrate of Trichoderma. Phytopathology 1936, 26, 1068-1070.

14. Cook, K.M.; Hilton, S.T.; Mecinovic, J.; Motherwell, W.B.; Figg, W.D.; Schofield, C.J. Epidithiodiketopiperazines block the interaction between hypoxia-inducible factor-1alpha (HIF-1alpha) and p300 by a zinc ejection mechanism. J. Biol. Chem. 2009, 284, 26831-26838. [CrossRef] [PubMed]

15. Gardiner, D.M.; Waring, P.; Howlett, B.J. The epipolythiodioxopiperazine (ETP) class of fungal toxins: Distribution, mode of action, functions, and biosynthesis. Microbiology 2005, 151, 1021-1032. [CrossRef]

16. Iwasa, E.; Hamashima, Y.; Sodeoka, M. Epipolythiodiketopiperazine alkaloids: Total syntheses and biological activities. Isr. J. Chem. 2011, 51, 420-433. [CrossRef]

17. Waring, P.; Eichner, R.D.; Mullbacher, A. The chemistry and biology of the immunomodulating agent gliotoxin and related epipolythiodioxopiperazines. Med. Res. Rev. 1988, 8, 499-524. [CrossRef]

18. Chai, C.L.; Waring, P. Redox sensitive epidithiodioxopiperazines in biological mechanisms of toxicity. Redox. Rep. 2000, 5, 257-264. [CrossRef] [PubMed]

19. Hurne, A.M.; Chai, C.L.; Waring, P. Inactivation of rabbit muscle creatine kinase by reversible formation of an internal disulfide bond induced by the fungal toxin gliotoxin. J. Biol. Chem. 2000, 275, 25202-25206. [CrossRef] [PubMed]

20. Eichner, R.D.; Waring, P.; Geue, A.M.; Braithwaite, A.W.; Mullbacher, A. Gliotoxin causes oxidative damage to plasmid and cellular DNA. J. Biol. Chem. 1988, 263, 3772-3777. [CrossRef]

21. Mullbacher, A.; Waring, P.; Tiwari-Palni, U.; Eichner, R.D. Structural relationship of epipolythiodioxopiperazines and their immunomodulating activity. Mol. Immunol. 1986, 23, 231-235. [CrossRef]

22. Tan, X.; Sun, L.; Li, Q.; Qi, C.; Fu, C.; Zhu, H.; Yang, X.; Feng, H.; Li, Y.; Zhang, Y.; et al. Secoemestrin C inhibits activation of $\mathrm{NKT} /$ conventional T cells and protects against concanavalin A-induced autoimmune hepatitis in mice. Am. J. Transl. Res. 2020, 12, 3389-3401.

23. Ooike, M.; Nozawa, K.; Kawai, K.-I. An epitetrathiodioxopiperazine related to emestrin from Emericella foveolata. Phytochemistry 1997, 46, 123-126. [CrossRef]

24. Seya, H.; Nozawa, K.; Udagawa, S.-I.; Nakajima, S.; Kawai, K.-I. Studies on fungal products. IX. Dethiosecoemestrin, a new metabolite related to emestrin, from Emericella striata. Chem. Pharm. Bull. 1986, 34, 2411-2416. [CrossRef] [PubMed]

25. Seya, H.; Nakajima, S.; Kawai, K.-I.; Udagawa, S.-I. Structure and absolute configuration of emestrin, a new macrocyclic epidithiodioxopiperazine from Emericella striata. J. Chem. Soc. Chem. Comm. 1985, 739, 657-658. [CrossRef] 
26. Seya, H.; Nozawa, K.; Nakajima, S.; Kawai, K.-I.; Udagawa, S.-I. Studies on fungal products. Part 8. Isolation and structure of emestrin, a novel antifungal macrocyclic epidithiodioxopiperazine from Emericella striata. X-ray molecular structure of emestrin. J. Chem. Soc. Perkin Trans. I 1986, 1986, 109-116. [CrossRef]

27. Nozawa, K.; Udagawa, S.-I.; Nakajima, S.; Kawai, K.-I. Studies on fungal products. XIV. Emestrin B, a new epitrithiodioxopiperazine, from Emericella striata. Chem. Pharm. Bull. 1987, 35, 3460-3463. [CrossRef]

28. Shin, D.S.; Kim, S.; Yang, H.C.; Oh, K.-B. Cloning and expression of isocitrate lyase, a key enzyme of the glyoxylate cycle, of Candida albicans for development of antifungal drugs. J. Microbiol. Biotechnol. 2005, 15, 652-655.

29. Hautzel, R.; Anke, H.; Sheldrick, W.S. Mycenon, a new metabolite from a Mycena species TA 87202 (Basidiomycetes) as an inhibitor of isocitrate lyase. J. Antibiot. 1990, 43, 1240-1244. [CrossRef]

30. Schoch, C.L.; Seifert, K.A.; Huhndorf, S.; Robert, V.; Spouge, J.L.; André Levesque, C.; Chen, W.; Fungal Barcoding Consortium. Nuclear ribosomal internal transcribed spacer (ITS) region as a universal DNA barcode marker for Fungi. Proc. Natl. Acad. Sci. USA 2012, 109, 6241-6246. [CrossRef]

31. Samson, R.A.; Visagie, C.M.; Houbraken, J.; Hong, S.-B.; Hubka, V.; Klaassen, C.H.W.; Perrone, G.; Seifert, K.A.; Susca, A.; Tanney, J.B.; et al. Phylogeny, identification and nomenclature of the genus Aspergillus. Stud. Mycol. 2014, 78, 141-173. [CrossRef] [PubMed]

32. Sharma, V.; Sharma, S.; Bentrup, K.H.Z.; McKinney, J.D.; Russell, D.G.; Jacobs, W.R., Jr.; Sacchettini, J.C. Structure of isocitrate lyase, a persistence factor of Mycobacterium tuberculosis. Nat. Struct. Biol. 2000, 7, 663-668. [CrossRef] [PubMed]

33. Kim, H.; Hwang, J.-Y.; Shin, J.; Oh, K.-B. Inhibitory effects of diketopiperazines from marine-derived Streptomyces puniceus on the isocitrate lyase of Candida albicans. Molecules 2019, 24, 2111. [CrossRef] [PubMed]

34. Lee, S.-H.; Moon, K.; Kim, H.; Shin, J.; Oh, D.-C.; Oh, K.-B. Bahamaolide A from the marine-derived Streptomyces sp. CNQ343 inhibits isocitrate lyase in Candida albicans. Bioorg. Med. Chem. Lett. 2014, 24, 4291-4293. [CrossRef] [PubMed] 